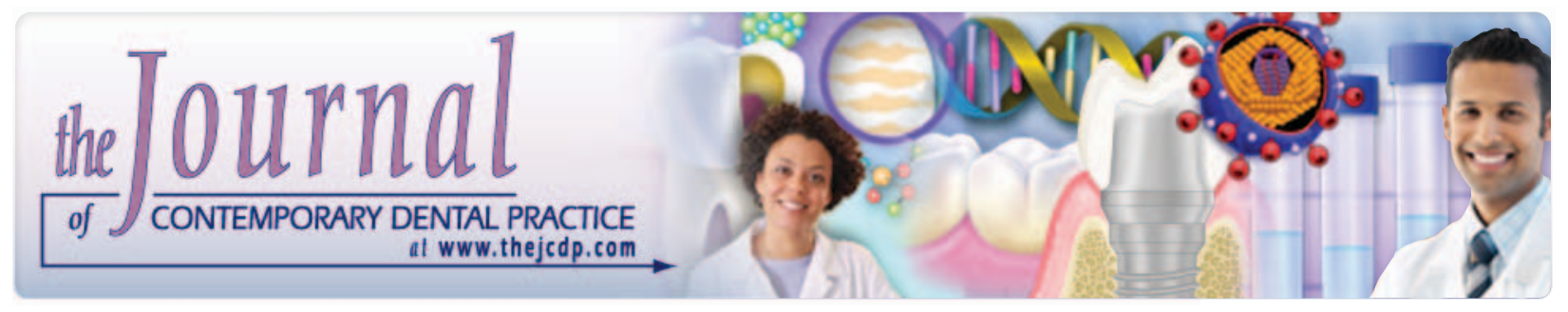

\title{
A Comparative Study of Surgical Morbidity Associated with Mandibular Third-Molar Surgery in Young and Aging Populations
}

Wasiu L. Adeyemo, BDS, FMCDS, DMD, FICS; Mobolanle O. Ogunlewe, BDS, FWACS; Akinola L. Ladeinde, BDS, FMCDS, FWACS; Olufemi O. Hassan, BDS; Olanrewaju A. Taiwo, BChD

\begin{abstract}
Aim: Prophylactic surgical extraction of impacted third molars is a common practice throughout the world justified on the presumption that the risk of surgical morbidity increases with increasing age, among other reasons. The aim of this study was to analyze and compare surgical morbidity associated with third-molar extractions in young and aging populations.

Methods and Materials: A review of records for all patients who underwent the surgical extraction of impacted third molars between April 2001 and June 2006 at the Lagos University Teaching Hospital was carried out.
\end{abstract}

Results: A total of 506 patients had surgical extractions of impacted third molars under local anaesthesia during the period of the study. Of these, 470 (92.9 percent) patients were below the age of 40 years (Group A) and 36 (7.1 percent) patients were 40 years of age and older (Group B). No incidences of severe intraoperative complications (excessive bleeding or mandibular fractures) were recorded in either group, but other postoperative complications were reported in 70 (13.8 percent) patients. Of these 70 patients, 65 (92.9 percent) were from Group A and 5 (7.1 percent) were from Group B, and their complications included infected socket, dry socket, paraesthesia, and buccal space abscess.

Conclusions: No significant difference in postoperative complications following surgical removal

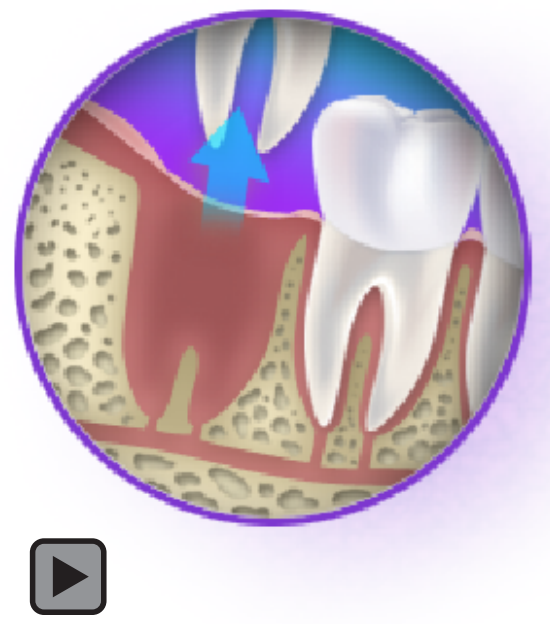

of mandibular third molars was found between patients 40 years old and greater and those below age 40. Prophylactic surgical extraction of impacted mandibular third molars, based on the assumption that surgical morbidity increases with age, may not be justifiable.

Clinical Significance: Age does not predispose patients who had surgical extraction of mandibular third molars above 40 years of age to any additional surgical complications when compared to patients below the age of 40 years receiving comparable treatment.

Keywords: Surgical morbidity, third-molar surgery, young, aging population, comparative study

Citation: Adeyemo WL, Ogunlewe MO, Ladeinde AL, Hassan OO, Taiwo OA. A Comparative Study 
of Surgical Morbidity Associated with Mandibular Third-Molar Surgery in Young and Aging Populations. J Contemp Dent Pract [Internet]. 2010 July; 11(4):001-008. Available from: http:// www.thejcdp.com/journal/view/volume11-issue4adeyemo

\section{Introduction}

Removal of impacted mandibular third molars (IMTM) is among the most common surgeries performed annually worldwide, and it represents a significant proportion of the outpatient surgical procedures performed by oral and maxillofacial surgeons..$^{1}$ Impaction of "wisdom" teeth, particularly in the mandibular arch, can predispose patients to conditions such as dental caries in the affected teeth themselves or adjacent teeth, pericoronitis, resorption of adjacent teeth, periodontal problems, and other associated pathologies. $\frac{2.3}{\text { The }}$ These conditions may ultimately lead to the extraction of these teeth.

In 1997, the Faculty of Dental Surgery of the Royal College of Surgeons of England published guidelines for the management of patients with impacted third molars. ${ }^{2}$ The endorsement of these guidelines by the National Institute for Clinical Excellence (NICE) of England in March 2000, with the added comment that a first episode of pericoronitis, unless particularly severe, should not be considered an indication for removal, made prophylactic extraction, in the absence of specific medical and surgical conditions, unjustifiable. ${ }^{4}$ Despite the fact that there are well-established indications for the extraction of impacted third molars, prophylactic removal of impacted third molars, free of any pathology, is still a common practice worldwide, especially in Europe and the United States. ${ }^{\underline{5}}$

Some authors have advocated the prophylactic removal of impacted third molars because of the increased risk with age of mandibular fractures as well as cysts and tumor development around the impacted teeth. ${ }^{6-8}$ Proponents of prophylactic removal also strongly believe that age may be used as an indicator for surgical removal of IMTM, as the risk of surgical morbidity increases with increasing age..$^{1,9}$ Therefore, early preventive removal between the ages of 15 and 21 years has been recommended, if normal eruption cannot be predicted. ${ }^{10}$
Third Molar Conditions

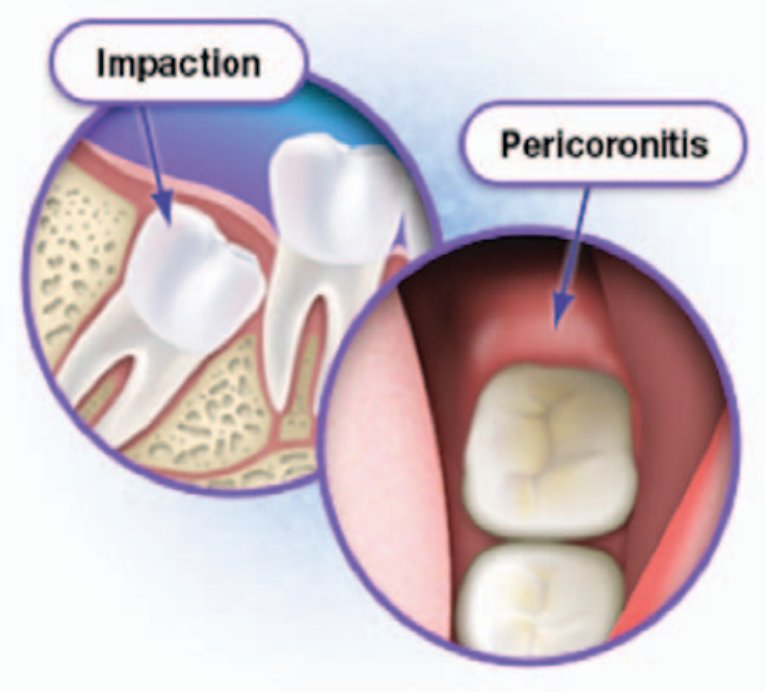

Therefore, the aim of this study was to analyze and compare the surgical morbidity associated with third-molar surgery in young (less than 40 years) and aging (40 years and above) populations at the Lagos University Teaching Hospital, Nigeria.

The null hypothesis was that the surgical morbidity associated with third-molar surgery in patients 40 years of age and above is no different from those patients below the age of 40 .

\section{Methods and Materials}

A retrospective review of treatment for patients who had surgical extraction of impacted mandibular third molars between April 2001 and June 2006 at the Lagos University Teaching Hospital was carried out. All cases were identified through patient records. Data collected included patients' age, gender, teeth extracted, indication for extraction(s), types of impaction(s), and surgical morbidity (intra- and post-operative complications). Only patients who had surgical extraction of at least one mandibular third molar were included in the study. Data were compared between patients $<40$ years (Group A) and those $\geq 40$ years (Group B).

The surgical procedure in all cases included the standard buccal guttering technique using rotary instruments under local anaesthesia. ${ }^{11}$ All patients returned for follow-up at one week. Patients without complications were discharged one week postoperatively after suture removal, and those 


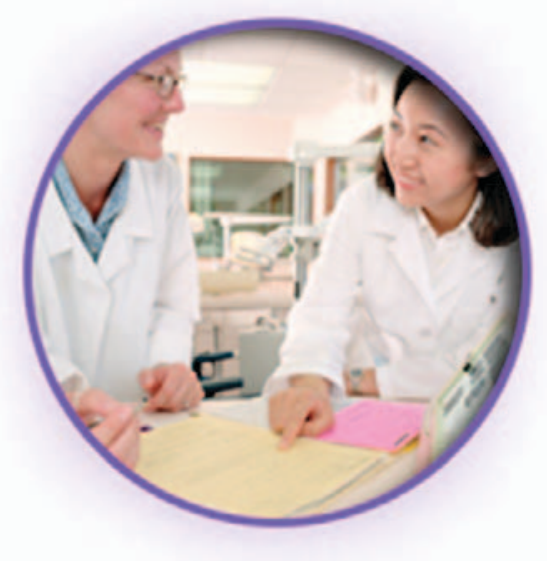

with complications were followed up until the resolution of symptoms or their loss to follow-up.

Data were analyzed using the SPSS for Windows (version 12.0; SPSS Inc., Chicago, IL, USA) statistical software package and presented in descriptive and tabular forms. Test of significance was used as appropriate, and the significance level was set at $p<0.05$. The correlation between age of patients and postoperative complications was analyzed with simple regression.

\section{Results}

A total of 506 patients (age range, 16-68 years) had surgical extraction(s) of impacted mandibular third molars under local anaesthesia during the study period. Of these, 470 (92.9 percent) were below the age of 40 years (Group A) and 36 (7.1 percent) patients were 40 years or above (Group B). Mean age (SD) of patients $<40$ years was $25.8 \pm 4.6$ years (range, $16-39$ years) and those of patients $\geq 40$ years was $47.6 \pm 7.2$ years (range, 40-68 years). Table 1 shows the gender distribution of patients in both groups $(p>0.05)$. The most common type of impaction (angulation) in both groups was mesioangular impaction (Table 2). Recurrent pericoronitis (87.9 percent) was the major reason for surgical extractions in both groups followed by dental caries (only 9.3 percent) (Table 3).

Minor intraoperative complications (tooth/ root fractures) were recorded in a few patients and were evenly distributed in the two groups $(p>0.05)$. No cases of excessive bleeding, mandibular fractures, or other severe intraoperative complications were recorded, but

Table 1. Gender distribution of patients in Groups A and B.

\begin{tabular}{|l|c|c|c|}
\hline \multicolumn{1}{|c|}{ Age Group } & Male & Female & Total (\%) \\
\hline $\mathrm{A}(<40$ years $)$ & 239 & 231 & $470(92.9)$ \\
\hline $\mathrm{B}(\geq 40$ years $)$ & 16 & 20 & $36(7.1)$ \\
\hline Total & 255 & 251 & $506(100)$ \\
\hline$p>0.05$ & \multicolumn{3}{|l|}{} \\
\hline
\end{tabular}

Table 2. Types of impaction.

\begin{tabular}{|l|c|c|c|}
\hline \multicolumn{1}{|c|}{$\begin{array}{c}\text { Type of } \\
\text { Impaction }\end{array}$} & \multicolumn{2}{c|}{$\begin{array}{c}\text { Number of patients } \\
\text { in each group }\end{array}$} & Total (\%) \\
\cline { 2 - 4 } & $\mathbf{A}$ (<40 years) & $\mathbf{B}$ ( $\mathbf{4 0 \text { years) }}$ & \\
\hline Mesioangular & 271 & 18 & $289(57.1)$ \\
\hline Horizontal & 79 & 6 & $85(16.8)$ \\
\hline Distoangular & 57 & 4 & $61(12.0)$ \\
\hline Vertical & 47 & 7 & $54(10.7)$ \\
\hline Linguo-angular & 2 & 1 & $3(0.6)$ \\
\hline Not indicated & 14 & 0 & $14(2.8)$ \\
\hline Total & 470 & 36 & $506(100)$ \\
\hline
\end{tabular}


Table 3. Indications for surgical extraction.

\begin{tabular}{|l|c|c|c|}
\hline \multirow{2}{*}{ Indications } & Number of patients & Total (\%) \\
\cline { 2 - 4 } & $\mathbf{A}$ (<40 years) & $\mathbf{B}(\mathbf{2 4 0}$ years) & $445(87.9)$ \\
\hline Pericoronitis & 415 & 30 & $44(8.7)$ \\
\hline Caries on M3* & 39 & 5 & $3(0.6)$ \\
\hline Caries on M2* & 2 & 1 & $2(0.4)$ \\
\hline Abscess & 2 & 0 & $3(0.6)$ \\
\hline Prophylactic & 3 & 0 & $9(1.8)$ \\
\hline Not Indicated & 9 & 0 & $506(100)$ \\
\hline Total & 470 & 36 & \\
\hline${ }^{*} \mathrm{M} 2=$ mandibular second molar; M3=mandibular third molar. \\
\hline
\end{tabular}

Table 4. Postoperative complications following third-molar surgery.

\begin{tabular}{|c|c|c|c|}
\hline \multirow{2}{*}{ Complications } & \multicolumn{2}{|c|}{ Number of patients } & \multirow{2}{*}{ Total $(\%)$} \\
\hline & $A(<40$ years) & $B$ ( $\geq 40$ years) & \\
\hline Infected socket & 38 & 3 & $41(58.6)$ \\
\hline Dry socket & 23 & 1 & $24(34.3)$ \\
\hline Paresthesia & 3 & $1^{*}$ & $4(5.7)$ \\
\hline Buccal abscess & 1 & 0 & $1(1.4)$ \\
\hline Total & 65 & 5 & $70(100)$ \\
\hline \multicolumn{4}{|c|}{$\begin{array}{l}(p>0.05) \\
{ }^{*} \text { Persistent for three months until lost to follow-up. }\end{array}$} \\
\hline
\end{tabular}

minor postoperative complications were reported in 70 (13.8 percent) patients. These complications were recorded in 65 out of 470 (13.8 percent) patients in Group A and in 5 out of 36 (13.9 percent) patients in Group B ( $p>0.05)$. The most common postoperative complication was an infected socket (58.6 percent). Table 4 shows different types of postoperative complications in both groups. Simple regression analysis of the entire studied population showed no significant positive correlation between age of patients and postoperative complications ( $\left.R^{2}=0.002, p=0.263\right)$.

Patients with dry socket, infected socket, and a buccal space abscess were treated and followed for one to four weeks until the symptoms resolved. Resolution of lower-lip paresthesia in Group A was observed between four and six weeks postoperatively. No resolution of the paresthesia occurred in the only patient in Group B after three months. Furthermore, this patient was subsequently lost to follow-up.

\section{Discussion}

During the pre-penicillin era, prophylactic removal of impacted wisdom teeth used to be the order of the day because of morbidity associated with pathologies related to these teeth. ${ }^{2}$ In recent times, prophylactic surgery has been justified on the basis that third molars have no definite role in the mouth ${ }^{12}$ and the need to minimize the risk of disease (cysts and tumors) development associated with the retention of these teeth. $\frac{7.9}{}$ In fact, between 18 and 56.5 percent of all third molars that have been removed by oral surgeons in the United Kingdom and the United States were disease free. ${ }^{13,14}$ Moreover, it has been shown that the incidence of cyst and tumor development associated with impacted third molars is low. ${ }^{15.16}$ Two other major arguments made by supporters of the prophylactic removal include the "relative" ease with which third molars can be extracted in younger people and the improved morbidity compared with an older age group..$^{17}$ 


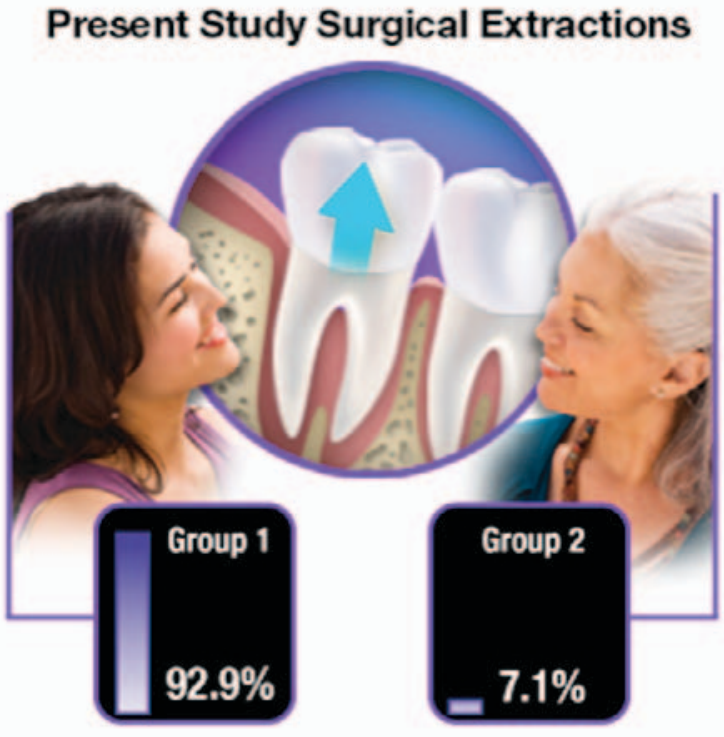

There are conflicting reports in the literature regarding age-related surgical morbidity following third-molar surgical extraction. Chuang et al. ${ }^{1}$ recently reported that increased age $(\geq 25$ years) appears to be associated with a higher complication rate for third-molar extraction. In fact, patients 25 years of age and over were statistically significantly more likely to experience a complication compared with their counterparts under the age 25 of years. ${ }^{1}$ This outcome contrasts sharply with findings from this and other reports that found no increased morbidity with increasing age following third-molar surgery. ${ }^{14,18-20}$

In fact, the present study found no significant difference in postoperative complications following surgical removal of mandibular third molars between patients 40 years old and greater and those below age 40. Complications occurred in 13.9 percent and 13.8 percent in Groups $A$ and $B$, respectively. A previous report explored the outcome of third-molar surgery and concluded that third-molar surgery in patients 25 years of age or older is associated with minimal morbidity, low postoperative complications, and minimal impact on the patients' quality of life. ${ }^{15}$ In other words, patients age 25 years or older can undergo third-molar surgery with minimal anticipated complications. ${ }^{14}$ Jerjes et al. ${ }^{19}$ also found no difference in complication between younger and older patients but a higher incidence of complications in patients treated by less-experienced surgeons. It is noteworthy that a simple linear regression analysis of the entire studied population showed no significant correlation between age of patients and postoperative complications.

The overall postoperative complication rate in the present study was 13.8 percent and, as stated previously, this outcome was equally distributed in both groups of patients. Because postoperative pain, swelling, and trismus were present in all patients, albeit at different degrees, they were, therefore, not considered a postoperative complication but rather surgical sequelae. Earlier studies have reported postoperative complications ranging from 14.2 to 29.3 percent. ${ }^{1,18,21}$ The most common complications in the present study were an infected socket and dry socket. In fact, dry socket has been reported as the most common complication of surgical extraction of impacted third molars. ${ }^{1.18,19}$ The incidence of inferior alveolar nerve injury leading to paresthesia of the lower lip was low in the present study, an outcome consistent with most previously published reports. $\stackrel{1,18,19,21}{ }$ Furthermore, all cases of paresthesia involved the inferior alveolar nerve. This is similar to another report in which the buccal surgical approach with the use of burs was used. $\frac{18}{}$ However, severe complications following third-molar surgery are rare..$^{1.14 .18 .19}$

Proponents of prophylactic removal believe that many asymptomatic impacted third molars, if left in situ, would eventually require removal later in life..$^{12}$ But how many of these impacted third molars, if left untreated, would develop symptoms or pathology sufficient to warrant surgical removal later in life? Brickley et al., ${ }^{22}$ in a study on the prevalence of third molars in an adult population, suggested that a large number of patients can expect to retain their mandibular third molars beyond the age of 35 years and that in many cases a conservative "wait and see" policy for mandibular third molars of patients in their early 20s is appropriate. It also has been reported that IMTM that have not been infected may be more likely to remain intact compared with other teeth at potential risk. ${ }^{23}$ In addition, about one in five people in their 30 s has at least one unerupted third molar, which can remain in situ throughout life without undergoing pathological changes. ${ }^{24}$

In the present study, just 7.1 percent of patients requiring removal of impacted third molars were 40 years and above. Previous authors also have noted a low incidence of third-molar surgical extraction in patients over 40 years of age. ${ }^{25,26}$ Obiechina et al. ${ }^{25}$ reported that less than 3 percent of patients requiring lower-third-molar surgery were over 40 years of age. 
Kaminishi et al., ${ }^{26}$ in a 2006 study in the United States, found that 10.5 percent and 17.3 percent of patients requiring removal of symptomatic impacted third molars over two study periods, 1992-1997 and 1997-2002, respectively, were more than 40 years old.

Mesioangularly impacted third molars were the most frequently seen in the present study, a finding that was in agreement with earlier studies from Nigeria ${ }^{18,25,27}$ and elsewhere. ${ }^{28.29}$ In this study recurrent pericoronitis was the major indication given for extraction. In contrast, recurrent pericoronal infection is considered the single most common indication for surgical removal of impacted third molars in all age groups. ${ }^{11,25,27,30}$

Surgical difficulty has been widely reported to be associated with advancing age $\frac{31-33}{\text { But }}$ the authors are of the opinion that the fear of increased difficulty of extraction with increasing age should not be the sole reason for prophylactic extraction of third molars. Susarla and Dodson ${ }^{34}$ also have shown that the difficulty of third-molar surgery is governed primarily by anatomic and operative considerations with minimal influence from demographic factors. This conclusion also has been supported by other authors..$^{19}$ Therefore, we recommend that surgical extraction should be carefully planned, taking into consideration all factors about the patient, the specific tooth involved, and the skill and experience level of the operator. If difficulty is anticipated, patients should be referred to an experienced oral and maxillofacial surgeon.

This report was a study based on a review of patient treatment records. As with any retrospective analysis of this type, some of the desired information may not always be recorded in a patient's chart for any number of reasons. Consequently, the retrospective nature of the present study did not afford the opportunity to standardize criteria for the assessment of complications, in particular, the rate of neurosensory deficit reported.

\section{Conclusions}

No significant difference was found in the postoperative complications following surgical removal of mandibular third molars between patients $\geq 40$ years and those below age 40 ; thus, the null hypothesis was accepted. Consequently, prophylactic surgical extraction of impacted lower mandibular molars, based on the assumption that surgical morbidity increases with age, may not be justifiable.

\section{Clinical Significance}

Age alone does not predispose patients 40 years old and older who undergo surgical extraction of mandibular third molars to any additional surgical complications as compared to patients below the age of 40 years.

\section{References}

1. Chuang SK, Perrott DH, Susarla SM, Dodson TB. Age as a risk factor for third molar surgery complications. J Oral Maxillofac Surg. 2007; 65(9):1685-92.

2. Westcott K, Irvine GH. Appropriateness of referrals for removal of wisdom teeth. $\mathrm{Br} \mathrm{J}$ Oral Maxillofac Surg. 2002; 40(4):304-6.

3. National Institutes of Health. Consensus development conference for removal of third molars. J Oral Surg. 1980; 38(3):235-6.

4. National Institute for Clinical Excellence (London). Guidance on the removal of wisdom teeth. 2000.

5. Werkmeister R, Fillies T, Joos U, Smolka K. Relationship between lower wisdom tooth position and cyst development, deep abscess formation and mandibular angle fracture. J Craniomaxillofac Surg. 2005; 33(3):164-8.

6. Glosser JW, Campbell JH. Pathologic change in soft tissues associated with radiographically "normal" third molar impactions. Br J Oral Maxillofac Surg. 1999; 37(4):259-60.

7. Güven O, Keskin A, Akal ÜK. The incidence of cysts and tumors around impacted third molars. Int J Oral Maxillofac Surg. 2000; 29(2):131-5.

8. Hanson BP, Cummings P, Rivara FP, John MT. The association of third molars with mandibular angle fractures: a meta-analysis. J Can Dent Assoc. 2004; 70(1):39-43

9. Baykul T, Saglam AA, Aydin U, Basak K. Incidence of cystic changes in radiographically 
normal impacted lower third molar follicles. Oral Sur Oral Med Oral Pathol Oral Radiol Endod. 2005; 99(5):542-5.

10. Laskin DM. Questions and answers. JAMA. 1984; 251:1876.

11. Bamgbose BO, Akinwande JA, Adeyemo WL, Ladeinde AL, Arotiba GT, Ogunlewe MO. Prospective, randomized, open-label, pilot clinical trial comparing the effects of dexamethasone coadministered with diclofenac potassium or acetaminophen and diclofenac potassium monotherapy after thirdmolar extraction in adults. Curr Ther Res Clin Exp. 2006; 67(4):229-40.

12. Rafetto LK. Removal of asymptomatic third molars: a supporting view. J Oral Maxillofac Surg. 2006; 64(12):1811-5.

13. Liedholm R, Knutsson K, Lysell L, Rohlin M. Mandibular third molars: oral surgeons' assessment of the indications for removal. $\mathrm{Br}$ J Oral Maxillofac Surg. 1999; 37(6):440-3.

14. Haug RH, Perrott DH, Gonzalez ML, Talwar RM. The American Association of Oral and Maxillofacial Surgeons Age-Related Third Molar Study. J Oral Maxillofac Surg. 2005; 63(8):1106-14.

15. Adeyemo WL. Do pathologies associated with impacted lower third molars justify prophylactic removal? A critical review of the literature. Oral Surg Oral Med Oral Pathol Oral Radiol Endod. 2006; 102(4):448-52.

16. Stephens RG, Kogon SL, Reid JA. The unerupted or impacted third molar-a critical appraisal of its pathologic potential. J Can Dent Assoc. 1989; 55(3):201-7.

17. Hill CM. Removal of asymptomatic third molars: an opposing view. J Oral Maxillofac Surg. 2006; 64(12):1816-20.

18. Gbotolorun OM, Olojede AC, Arotiba GT, Ladeinde AL, Akinwande JA, Bamgbose BO. Impacted mandibular third molars: presentation and postoperative complications at the Lagos University Teaching Hospital. Nig Q J Hosp Med. 2007; 17(1):26-9.

19. Jerjes W, El-Maaytah M, Swinson B, Banu B, Upile T, D'Sa S, Al-Khawalde W, Chaib B, Hopper C. Experience versus complication rate in third molar surgery. Head Face Med. 2006; 2:14.

20. Scheer MJ. Removal of asymptomatic impacted wisdom teeth. JAMA. 1984; 252(11):1410-1.

21. Oginni FO, Ugboko VI, Assam E, Ogunbodede EO. Postoperative complaints following impacted mandibular third molar surgery in lle-lfe, Nigeria. SADJ. 2002; 57(7):264-8.

22. Brickley MR, Tanner M, Evans DJ, Edwards MJ, Armstrong RA, Shepherd JP. Prevalence of third molars in dental practice attenders aged over 35 years. Community Dent Health. 1996; 13(4):223-7.

23. Yamaoka M, Furusawa K, Tambo A, Imai S. Remaining mandibular third molars in an adult population. J Oral Rehabil. 1997; 24(12):895-8.

24. Hugoson A, Kugelberg CF. The prevalence of third molars in a Swedish population. An epidemiological study. Community Dent Health. 1988; 5(2):121-38.

25. Obiechina AE, Arotiba JT, Fasola AO. Third molar impaction: evaluation of the symptoms and pattern of impaction of mandibular third molar teeth in Nigerians. Odontostomatol Trop. 2001; 24(93):22-5.

26. Kaminishi RM, Lam PS, Kaminishi KS, Marshall MW, Hochwald DA. A 10-year comparative study of the incidence of third molar removal in the aging population. J Oral Maxillofac Surg. 2006; 64(2):173-4.

27. Obiechina AE, Oji C, Fasola AO. Impacted mandibular third molars: depth of impaction and surgical methods of extraction among Nigerians. Odontostomatol Trop. 2001; 24(94):33-6.

28. Kruger E, Thomson WM, Konthasinghe P. Third molar outcomes from age 18 to 26 : findings from a population-based New Zealand longitudinal study. Oral Surg Oral Med Oral Pathol Oral Radiol Endod. 2001; 92(2):150-5.

29. Koerner KR. The removal of impacted third molars. Principle and procedures. Dent Clin North Am. 1994; 38(2):255-78.

30. Bruce RA, Frederickson GC, Small GS. Age of patients and morbidity associated with mandibular third molar surgery. J Am Dent Assoc. 1980; 101(2):240-5.

31. Gbotolorun OM, Arotiba GT, Ladeinde AL. Assessment of factors associated with surgical difficulty in impacted mandibular third molar extraction. J Oral Maxillofac Surg. 2007; 65(10):1977-83.

32. Renton T, Smeeton N, McGurk M. Factors predictive of difficulty of mandibular third molar surgery. Br Dent J. 2001; 190(11):607-10.

33. Benediktsdóttir IS, Wenzel A, Petersen JK, Hintze $\mathrm{H}$. Mandibular third molar removal: risk indicators for extended operation time, postoperative pain, and complications. Oral 
Surg Oral Med Oral Pathol Oral Radiol Endod. 2004; 97(4):438-46.

34. Susarla SM, Dodson TB. Risk factors for third molar extraction difficulty. J Oral Maxillofac Surg. 2004; 62(11):1363-71.

\section{About the Authors}

\section{Wasiu L. Adeyemo, BDS, FMCDS, DMD, FICS (Corresponding Author)}

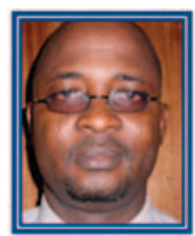

Dr. Adeyemo is a senior lecturer/ consultant oral and maxillofacial surgeon in the Department of Oral and Maxillofacial Surgery, College of Medicine, University of Lagos/ Lagos University Teaching Hospital, Lagos, Nigeria. He is a fellow of both the National Postgraduate Medical College of Nigeria and the International College of Surgeons. His research interests include craniofacial/cleft lip and palate defects genetic research, healing of bone grafts, and maxillofacial trauma. He also has a special interest in biomedical and research bioethics.

e-mail: lanreadeyemo@yahoo.com

\section{Mobolanle O. Ogunlewe, BDS, FWACS}

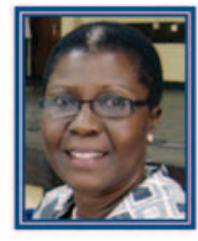

Dr. Ogunlewe is an associate professor/consultant oral and maxillofacial surgeon in the Department of Oral and Maxillofacial Surgery, College of Medicine, University of Lagos/Lagos University Teaching Hospital, Lagos, Nigeria. She is a fellow of the West African College of Surgeons. Her research interests include craniofacial/cleft lip and palate defects genetic research and diagnosis/ management of nonodontogenic tumors. She is currently the chairperson, Medical Advisory Committee (CMAC) of the Lagos University Teaching Hospital.
Akinola L. Ladeinde, BDS, FMCDS, FWACS

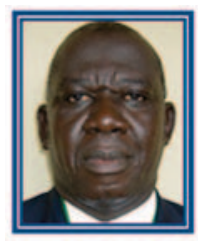

Dr. Ladeinde is an associate professor/consultant oral and maxillofacial surgeon in the Department of Oral and Maxillofacial Surgery, College of Medicine, University of Lagos/Lagos University Teaching Hospital, Lagos, Nigeria. He is a fellow of both the West African College of Surgeons and the National Postgraduate Medical College of Nigeria. His research interests include craniofacial/cleft lip and palate genetic research, diagnosis/management of odontogenic tumors, and orofacial reconstruction.

Olufemi O. Hassan, BDS

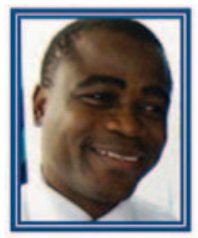

Dr. Hassan currently is a senior registrar in the Department of Oral and Maxillofacial Surgery, Lagos University Teaching Hospital, Lagos, Nigeria. He graduated with a Bachelor of Dental Surgery (BDS) from the University of Lagos. He is currently working on a research topic: The effect of dexamethasone administration on QoL after mandibular third-molar surgery.

Olanrewaju A. Taiwo, BChD

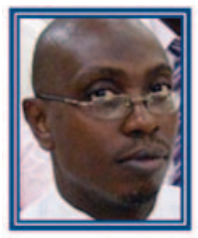

Dr. Taiwo currently is a senior registrar in the Department of Oral and Maxillofacial Surgery, Lagos University Teaching Hospital, Lagos, Nigeria. He graduated with a Bachelor of Dental Surgery (BChD) from Obafemi Awolowo University, Ile-lfe, Osun State, Nigeria. He is currently working on a research topic: Surgical management of cleft lip and palate deformities. 